\title{
Forming Lineages by Sticking Together
}

\author{
Makmiller Pedroso*
}

\begin{abstract}
Nature is replete with borderline cases that fall somewhere between organisms and communities. One broad class of borderline cases are microbial groups partially formed by the aggregation of cells from the environment, such as slime molds and dental plaque. Some have argued that microbial aggregates do not form lineages because microbial aggregates can acquire cells from the surrounding environment. Nevertheless, Haber (2016) has recently suggested that microbial aggregates may form lineages, but he does not fully elaborate his position. This paper argues that Haber's suggestion is correct as long as a permissive criterion of what constitutes a 'lineage-generating entity' is adopted. Different mechanisms for lineage formation in microbial aggregates will be described to motivate this argument. Unlike mammals, lineage formation in microbial aggregates is more dependent on ecological factors and does not produce well-defined parent-offspring relations. Yet, focusing on the formation of incipient lineages has the benefit of improving our understanding of the processes that hold microbial aggregates together, and it helps bridge the gap between the literature on biological individuality and recent work on microbial communities.
\end{abstract}

\section{Keywords}

species $\bullet$ organism $\bullet$ evolution $\bullet$ biological individual $\bullet$ lineage $\bullet$ aggregation $\bullet$ biofilm

Part of the special issue Species in the Age of Discordance, guest-edited by Matthew H. Haber and Daniel J. Molter.

*Philosophy \& Religious Studies, Towson University, 8000 York Road, Towson, MD 21252, USA, mpedroso@towson.edu

Received 12 December 2017; Revised 1 September 2018; Accepted 12 September 2018

doi:10.3998/ptpbio.16039257.0011.016 


\section{Introduction}

Nature is replete with borderline cases that fall somewhere between organisms and communities, such as lichens, biofilms, and the Portuguese Man-of-War. At first glance, the existence of such borderline cases might suggest that the concept of what constitutes an organism is too fuzzy to be useful in evolutionary biology. Yet, the notion of organisms is entrenched within central debates in evolution, including discussions over how fitness should be measured (Clarke 2010), what the bearers of adaptations and fitness are (Lloyd 2012; Huneman 2013), and the status of holobionts (Skillings 2016; Chiu and Eberl 2016). Finally, accounts of organisms can set the stage for explanations of how multicellularity evolved. In particular, characterizing multicellular organisms in terms of the level of cooperation between their cells suggests that their evolution required the presence of mechanisms that could suppress conflict between cells (Bourke 2011; Rainey and De Monte 2014; Queller 1997).

The obstacles associated with defining organisms bear striking similarities to the obstacles faced by definitions of species (Clarke and Okasha 2013). As the debate over the species status of red wolves illustrates, sometimes it is unclear whether a population forms a separate species or is a member of an existing species (Cahill et al. 2016). One way to address borderline cases of species is to follow David Hull (1978) into thinking that species are 'lineage segments' in the sense that species are ancestral-descendant sequences of populations (De Queiroz 1998, 2007; Richards 2010; Ereshefsky 2001, 2014). Similar to species, however, other levels in the biological hierarchy also produce lineages. For example, while animals often form lineages via sexual reproduction, genes produce lineages via replication. As a result, multiple authors have applied Hull's approach to different levels in the biological hierarchy (Haber 2016; Eldredge 1985; D. Hull 1980; Vrba and Eldredge 1984).

This paper discusses the prospects of applying Hull's approach to borderline cases of organisms. Multicellular aggregates built by microbes, such as dental plaque and slime molds, will be used as test cases. These microbial structures are particularly useful for evaluating Hull's approach because they possess certain features associated with organisms (e.g., division of labor) even though their constituent cell lineages do not necessarily run in tandem (Ereshefsky and Pedroso 2015; Bapteste et al. 2012; Ereshefsky and Pedroso 2013). In fact, some authors have claimed that microbial groups such as biofilms probably do not form lineages because they are assembled via the aggregation of cells from the environment (Doolittle 2013; Doolittle and Booth 2017; Clarke 2016; Booth 2014). Matt Haber (2016) has recently suggested that some microbial aggregates may form lineages, but he does not fully elaborate on his position. The goal of this paper is to evaluate Haber's suggestion.

This paper provides a theoretical argument-albeit informed by empirical studies-that Haber's suggestion is correct as long as a permissive concept of a 'lineage-generating entity' is adopted. According to this concept, microbial aggregates are lineage-generating entities not because they produce well-defined parent-offspring relations, but because they enable some of their component cell lineages to run in tandem. For instance, genetically related cells within biofilms tend to stay together because they live embedded in a sticky matrix (Nadell, Drescher, and Foster 2016). In this way, microbial aggregates can be understood as functioning as 'scaffolds' that facilitate the evolution of lineages within them (Griesemer 2016). Focusing on the positive assortment of cell lineages helps us understand what holds microbial aggregates together (Van Gestel et al. 2014), and how multicellularity might have evolved from unicellular ancestors (De Monte and Rainey 2014). Finally, adopting a more permissive account of lineagegenerating entities has the benefit of bridging the gap between the literature on biological individuality and recent work on microbial communities.

๑ OPEN ACCESS - PTPBIO.ORG 
This paper is divided into two sections. The first section introduces the lineage-based view of biological individuality proposed by Haber (2016) and others. The second section applies this view of biological individuality to microbial groups that are formed via aggregation, such as slime molds and dental plaque.

\section{Individual Thinking}

\subsection{Species, individuals, and fuzzy boundaries}

If we only knew about the organisms that most people are familiar with such as dogs, cats and other people, we would probably endorse the following concept of species: organisms come in different kinds, such as cats and dogs; these kinds are non-overlapping (that is, these kinds do not have members in common); and members of the same kind (or species) look alike. This view of species may be called 'the common sense view of species. has the benefit of being straightforward, but it fails to accommodate less parochial examples. In particular, this view of species conflicts with the fact that boundaries between species are not always well-marked. Moreover, the existence of borderline cases of species is expected since the evolution of new species is often a gradual process (Coyne and Orr 2004). A major limitation of the common sense concept of species is, therefore, that variation between species is not always discontinuous.

Motivated by developments in phylogenetic systematics during the 1970s, David Hull (1978) argued that species should be conceptualized as 'biological individuals.' 2 According to his view, species are "spatiotemporally restricted" entities in the sense that conspecific organisms must be linked by ancestor-descendant relationships. Organisms can share a recent ancestor but look radically dissimilar (e.g., the rapid evolution of birds from dinosaurs), and organisms may look similar without sharing a recent ancestor by virtue of convergent evolution. Hull's position implies that conspecific organisms can change in an open-ended fashion, and that genealogically unrelated organisms must belong to different species no matter how similar they are. In a nutshell, his proposal is that species membership should be tied to common ancestry rather than shared similarities. As a result, Hull's account has the benefit of providing a concept of species that does not assume that variation between species is discontinuous.

Several authors have further developed the view that species are individuals after Hull's original paper (e.g., De Queiroz 2007; Richards 2010; Ereshefsky 2010; Sober 1980). Still, their positions share Hull's assumptions that species taxa should be conceptualized as lineage segments, and that ancestor-descendant relationships are better at handling borderline cases of species than shared similarities. In order to motivate these assumptions, consider a schematic representation of a speciation event as shown in Figure 1. Since speciation is often a gradual process, 'gray zones' are expected to evolve in which it may be indeterminate whether there are two or one species. However, modeling species as non-overlapping kinds treats gray zones as exceptions and, consequently, the question of how gray zones generally evolve becomes neglected. In contrast, the evolution of gray zones is expected if species are conceptualized as lineage seg-

1. Note that the common sense view of species is not identical to the view that species are natural kinds. That is because prominent accounts of natural kinds allow for vague boundaries (e.g., Boyd 1999; Devitt 2008) or define kinds in terms of relational properties rather than shared similarities (e.g., Laporte 2004; Okasha 2002).

2. Michael Ghiselin's (1974) is also credited with introducing the view that species should be thought as biological individuals, but this paper focuses on Hull's version of this view instead. 


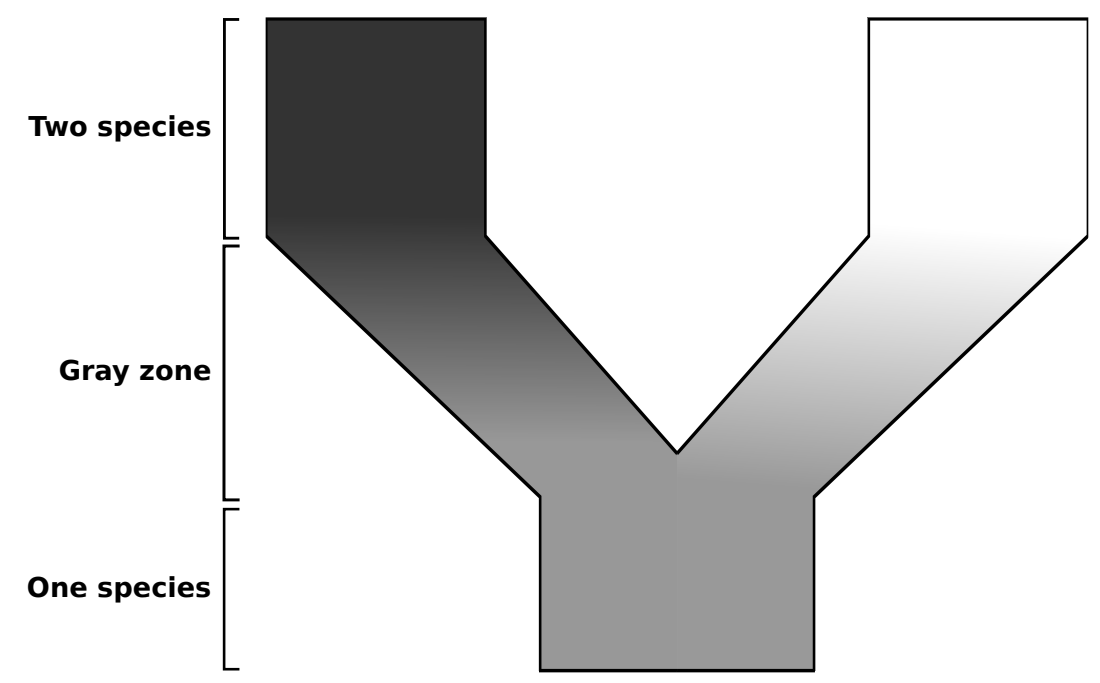

Figure 1: A schematic representation of a species splitting into two other species over time. This figure is based on De Queiroz (2007), Figure 1. Figure by author.

ments. ${ }^{3}$ As a result, viewing species as biological individuals appears to be especially suited to the study of the evolution of borderline cases of species.

Like with species, controversies over definitions of organism often stem from disagreements over how to handle borderline cases of organisms (Clarke and Okasha 2013). The folk concept of 'organism' is suitable for familiar organisms, such as dogs and cats, but not when applied to less familiar life forms, such as lichens and slime molds. Moreover, one major challenge for definitions of organisms is that the features commonly used to determine whether something is an organism, such as physiological integration, vary in degrees (Pepper and Herron 2008). Accordingly, satisfactory accounts of organisms and species are expected to handle borderline cases (Clarke and Okasha 2013). This suggests that Hull's view of species might be co-opted to tackle the question of how borderline cases of organisms should be characterized. This is precisely the position that will be discussed in the next section.

\subsection{Individual thinking and the problem of paradigm}

Hull's 1978 account of species illustrates a strategy for producing biological classifications which states that being causally connected by ancestor-descendant relationships takes priority over being similar. As Ereshefsky (2010) suggests, Hull's strategy for defining species might be called "individual thinking." ${ }^{4}$ In fact, multiple authors have relied on D. L. Hull (1978) to propose that, in addition to species, other levels of the biological hierarchy should be viewed as biological individuals, such as higher taxa and organisms (e.g., Haber 2016; Eldredge 1985; Vrba and Eldredge 1984; D. Hull 1980). Their proposal suggests that different levels of the biological hierarchy can be thought of as "lineage-generating entities" (Haber 2012). This account of the biological hierarchy sounds sensible, but is it useful when applied to lichens and other borderline cases of organisms?

3. Modeling species as lineage segments leads to the question of how population lineages should be individuated. See Sterner (2017) for a recent discussion of this topic.

4. In more detail, Ereshefsky (2010) discerns two strategies for producing classifications in science. 'Kind thinking' identifies "similarities that can be used in successful induction and explanation" (678). The classification of chemical elements in terms of atomic numbers is an example of kind thinking. Hull's account of species is a case of 'individual thinking' in that conspecific organisms must be "appropriately causally related" rather than being similar. 
Biologists and philosophers have developed multiple ways of categorizing borderline cases of organisms (Wilson and Sober 1989; Folse and Roughgarden 2010; Bouchard and Huneman 2013; Herron et al. 2013; D. Hull 1980; Godfrey-Smith 2015, 2013; Clarke 2013). A common strategy is to assume that being an organism is a matter of degree and, accordingly, that some collectives are more organism-like than others (Pepper and Herron 2008; Queller and Strassmann 2016, 2009; Díaz-Muñoz et al. 2016; Haber 2013). By relying on a particular metric, such as the level of physiological integration (e.g., Pradeu 2012), gradient accounts of organisms provide a unified account of a whole spectrum of organism-like structures, from microbial consortia to humans.

Gradient approaches to organisms typically select a paradigmatic organism case against which the other organism-like structures are contrasted with (Pepper and Herron 2008). For instance, one might assume that paradigmatic organisms are genetically homogeneous and, accordingly, that collectives can be more or less organism-like depending on their genetic homogeneity (Santelices 1999). A potential challenge with gradient approaches is that the choice of the paradigmatic cases might be arbitrary and biased towards mammals which, in turn, might cause us to neglect alternative ways evolution can produce organism-like structures (Ereshefsky and Pedroso 2015; O’Malley and Dupré 2007; McConwell 2017; Dupré and O'Malley 2009). Moreover, given the diversity of life in nature, the supposition that there exists a single type of paradigmatic organism should invite some skepticism. This is essentially what Haber (2013) calls the problem of paradigm with gradient accounts of organisms; viz., "the presumption of a paradigmatic organism against which all others must be judged" (196).

This 'problem of paradigm' suggests that individual thinking is especially useful when it comes to borderline cases of organisms. Biological individuals do not seem to face the problem of paradigm because they are defined in terms of common ancestry rather than shared similarities (Haber 2013). 5 Consequently, there is no presumption that there is a single type of paradigmatic organism that other organism-like collectives should be contrasted with. In this way, individual thinking appears to provide a better strategy for capturing the diversity of organism-like collectives when compared to gradient approaches. Still, the utility of individual thinking ultimately depends on whether it can be successfully applied to particular biological cases. Motivated by the fact that borderline cases of organisms are ubiquitous in the microbial world (Claessen et al. 2014), the next section applies individual thinking to microbial groups that are formed by aggregation, such as dental plaque and slime molds. As will be discussed, individual thinking is useful to understand how microbial aggregates hold together but, in order to accomplish that, the criterion of what counts as a 'lineage-generating entity' should be relaxed. Nonetheless, a more permissive concept of lineage-generating entity has a better chance of capturing the less paradigmatic cases of organisms.

5. The expression "biological individual" is often used in the literature to refer to the units of selection; i.e., the units upon which natural selection operates. In particular, multiple authors follow Lewontin (1970), who espouses that the units of selection should exhibit heritable variation in fitness. The expression "biological individual" is being used in a different sense in this paper. The reason for this is that a level in the biological hierarchy can form lineages without being units of selection. For instance, the assumption that biological species form lineages does not imply that species are units of selection. A further argument would need to be provided to show that the type of lineage produced by species also exhibit heritable variation in fitness. Particular levels in the biological hierarchy such as genes can form lineages and be units of selection, but that is not necessarily always the case. I thank one of the reviewers for asking me to clarify this point.

6. Haber's position is analogous to 'species eliminativism' in biological systematics according to which the species rank has outlived its usefulness and, for this reason, should be eliminated (e.g., Mishler 1999; Ereshefsky 2001). Similarly, Haber (2013) claims the concept of organism should be abandoned because the concept of 'organism' can obfuscate matters in that it can push certain biological factors into the background. 


\section{Applying Individual Thinking to Microbial Examples}

\subsection{The challenge posed by aggregation}

Microbes often live in association with multicellular structures which are assembled in different ways (Claessen et al. 2014; Bonner 1998; Grosberg and Strathmann 2007). Cells might fail to completely separate after cell division as in the case of filamentous cyanobacteria and the 'snowflake' yeast (Schirrmeister, Antonelli, and Bagheri 2011; Ratcliff et al. 2015; Ratcliff et al. 2012). Alternatively, microbial clusters can be partially formed via the aggregation of different cells as illustrated by biofilms and slime molds (Hall-Stoodley, Costerton, and Stoodley 2004; Gadagkar and Bonner 1994; Tarnita, Taubes, and Nowak 2013). This section focuses on microbial groups formed via aggregation.

One major difficulty in applying individual thinking to microbial aggregates is that they do not form parent-offspring relations (Ereshefsky and Pedroso 2015; Bapteste et al. 2012). Some animals possess a development program that ensures the assembly of a new organism is a closed process' in the sense that every cell in the adult organism comes from cell division from the same cell (e.g., zygote). In contrast, the assembly of microbial aggregates is an 'open process' in that cells which happen to be in the vicinity can join the aggregate (Leigh 1995; Bourke 2011). As a result, the cell lineages in microbial aggregates do not necessarily run in tandem across successive aggregates.

Microbial aggregates are unlikely to form biological individuals if their composition constantly changes over time due to aggregation. Some authors have claimed that aggregation probably causes the composition of microbial communities to drastically change over time (Clarke 2016; Doolittle and Booth 2017; Booth 2014). Recent work from microbial ecology does support this claim (Boon et al. 2014). For example, Burke et al. (2011) found that the composition of the microbial communities associated with a type of green alga are highly variable. According to this study, even though different microbial communities expressed similar functionality-e.g., they produced a sticky matrix, the microbial communities colonizing different algal hosts were highly variable. That is, all the communities expressed similar functions, but those functions were often implemented by different types of microbes. As Burke et al. (2011) elaborate, this observed pattern is probably due to a combination of deterministic and stochastic factors. A microbe must possess some capabilities in order to associate with the alga, but distantly related microbes can share the same abilities. As a result, the microbes that associated to the alga were those able to perform a particular function (deterministic factor), but that also happened to be in the vicinity (stochastic factor).

At first glance, the stochastic factor associated with aggregation seems to undercut Haber's (2016) suggestion that individual thinking can be fruitfully applied to microbial aggregates. However, there also exist examples of microbial communities that are formed by aggregation with cells that are highly genetically related. A striking example involves multicellular fruiting bodies formed by the amoeba Dictyostelium discoideum. Even though these fruiting bodies are formed via aggregation, fruiting bodies living in the wild exhibited high levels of genetic relatedness (Gilbert and Foster 2007). In fact, the genetic relatedness of the collected fruiting bodies turned out to be higher than most eusocial insect colonies. Studies such as this one indicate that the stochastic component associated with aggregation can be somehow constrained.

7. This is not to say that incomplete fission cannot occur during biofilm formation. In particular, Bacillus subtilis cells form chains due to incomplete cell division at the onset of biofilm formation but, as the biofilm continues to grow, the chains break apart which allows their cells to detach from each other (Vlamakis et al. 2013; Kobayashi 2007).

๑ OPEN ACCESS - PTPBIO.ORG 
It is not true that aggregation necessarily causes a microbial collective to constantly change its composition in an open-ended fashion (Pedroso 2017). [8

The next section discusses different evolutionary processes that can limit the amount of variation within a microbial aggregate (see Table 1 below for an outline). It will be suggested that these processes might facilitate the evolution of 'incipient lineages.'

\subsection{The evolution of incipient lineages}

Microbial aggregates can be composed by genetically related cells due to founder effects in which a new population starts with a few members of the original population (Pedroso 2018). An instructive class of cases consists of pathogen populations that pass through bottlenecks when infecting a new host (Abel et al. 2015). For example, direct visualization of the diarrhea-causing pathogen Vibrio cholerae during the infection of the small intestine in infant mice shows that microbial aggregates are mostly founded by single cells (Millet et al. 2014). The assumption that the composition of microbial aggregates are bound to change in an open-ended fashion loses its force once the ecological circumstances-e.g., host-pathogen interactions-are taken into account. Moreover, recognizing that some microbial aggregates are composed of genealogically related components partially explains their resilience because high genetic relatedness can suppress the evolution of cheater cells via kin selection (Griffin, West, and Buckling 2004; Gilbert and Foster 2007).

Cells within microbial aggregates are not always genetically related, however. In particular, biofilms are typically genetically diverse communities that are composed by multiple species (Nadell, Xavier, and Foster 2009; Stewart and Franklin 2008). As a result, one might think that tracking genealogical relationships is of limited utility in the case of a multispecies biofilms - or other diverse aggregates-because new cell types are continuously acquired from the environment. Still, the spatial distribution of genetic variants within a biofilm is often non-random (Elias and Banin 2012). Cells within a biofilm tend to form clonal patches since microbial cells undergo clonal division in a viscous matrix (Flemming and Wingender 2010). Additionally, differences in metabolic capabilities can cause cells in a biofilm to be spatially structured in a particular way (Stewart and Franklin 2008). For instance, a species can form a mantle over another species in a biofilm depending on the type of symbiotic relationship (Hansen et al. 2007).

The fact that biofilms are often spatially structured communities suggests that tracking genealogical relationships within a biofilm may help with understanding their dynamics. For example, computer simulations and empirical evidence indicate that cell lineages can segregate from each other as a biofilm grows (Nadell, Foster, and Xavier 2010; Kreft 2004; Van Gestel et al. 2014). Specifically, Van Gestel et al. (2014) observed that cell lineages in B. subtilis biofilms tended to segregate when the cell density of the founding population was low, but not when it was high. The evolution of lineage segregation is, in turn, relevant to explain the persistence of cooperation within biofilms because cooperators are more likely to persist in a population when they are spatially segregated from non-cooperators (Fletcher and Doebeli 2009). Hence, tracking lineages might be crucial for understanding the dynamics of microbial aggregates even when they are composed of multiple strains.

8. Gilbert and Foster (2007) suggest that the observed high genetic relatedness of fruiting bodies might have been caused by kin discrimination or limited dispersal. See Strassmann, Gilbert, and Queller (2011) for a discussion of kin discrimination in microbes. 


\begin{tabular}{ll}
\hline Mechanism & Examples \\
\hline Founder effects & Infection of a new host (Abel et al. 2015); \\
& V. cholerae colonization (Millet et al. 2014). \\
Lineage segregation & Simulations of biofilm growth (Nadell, Foster, and Xavier 2010); \\
& B. subtilis biofilms (Van Gestel et al. 2014). \\
Lineage assortment & Clumping dispersal (Hall-Stoodley and Stoodley 2005); \\
& Coaggregation (Rickard et al. 2003); \\
& Kin discrimination (Strassmann, Gilbert, and Queller 2011). \\
\hline
\end{tabular}

Table 1: Mechanisms for incipient lineage formation in microbial aggregates.

Although not every cell lineage runs in tandem across successive biofilms, a case could be made that some cell lineages might stay together across different biofilms depending on the type of dispersal. One type of dispersal in biofilms involves releasing individual cells into the environment ( $\mathrm{McD}$ Dougald et al. 2011). In other cases, however, dispersal cells can travel in clumps that are shed from the biofilm due to environmental disturbances, such as fluid shear (Hall-Stoodley and Stoodley 2005; Hall-Stoodley, Costerton, and Stoodley 2004). Clumping dispersal could cause some cell lineages that tend to occur close to each other to travel together across biofilms. Although biofilms do not form well-defined parent-offspring relations as some animals do, biofilms could still share some of their component lineages via clumping dispersal.

Microbial aggregates are more likely to share lineages if there is a mechanism that 'chooses' which types of cells could join a newly formed aggregate. In fact, 'co-aggregation mechanisms' do exactly that by relying on a system of molecular receptors to determine which pair of species can attach to each other in a biofilm (Rickard et al. 2003). 9 Co-aggregation illustrates that mixed biofilms do not necessarily pick up any cells that happen to be nearby. Furthermore, co-aggregation mechanisms can enable symbiotic interactions between different strains. 10 For example, two species associated with dental plaque formation, Streptococcus oralis and Actinomyces naeslundii, were observed to grow under certain conditions when co-aggregated, but not when alone (Palmer et al. 2001).

Table 1 summarizes the three mechanisms that cause cell lineages to stay together: founder effects, lineage segregation, and lineage assortment. Founder effects can increase the genetic relatedness of the cells in an aggregate via exogenous factors, such as finite resources and host defense mechanisms. Lineage segregation can cause cooperative cells to segregate from cheater cells due to the mechanical features associated with biofilm growth. Finally, lineage assortment can increase the chance that certain cell lineages will co-occur. These mechanisms can also operate simultaneously. For instance, the study by Van Gestel et al. (2014) mentioned previously discusses how founder effects can drive lineage segregation. These previously mentioned mechanisms are, in turn, relevant to understand the evolutionary dynamics of microbial aggregates. Founder effects and lineage segregation can restrain conflict within an aggregate by increasing the chance that cooperators interact with other cooperators. Additionally, lineage assortment can facilitate synergistic interactions within microbial aggregates by increasing the chance that certain cell types will aggregate with each other.

9. This is not to say that some strains can co-aggregate with multiple partners. Fusobacterium nucleatum can, for instance, co-aggregate with multiple oral bacterial species (Kolenbrander et al. 2010).

10. Additionally, synergistic interactions between strains can facilitate the evolution of more obligate partnerships via loss-of-function mutations (Morris, Lenski, and Zinser 2012). 
Altogether, the mechanisms cited above suggest that microbial aggregates can be thought of as lineage-generating entities. Microbial aggregates would be lineage-generating entities not because they produce well-defined parent-offspring relations as some mammals do, but because they enable their component cell lineages to stay together. To use Griesemer's (2016) apt term, microbial aggregates function as a type of 'scaffold' that facilitate the evolution of lineages within them by enabling some of their cell lineages to stick together. For instance, biofilms that disperse by shedding clumps enable some of their cell lineages to travel together across biofilms even though not every cell lineage in a biofilm runs in tandem during dispersal. Similarly, cell lineages within biofilms can remain together during growth due to lineage segregation. The mechanisms mentioned in Table 1 thus suggest that being a lineage-generating entity is not an all-or-nothing affair, but a matter of degree. Accordingly, as Haber (2016) proposes, microbial aggregates can be represented as lineage-generating entities after all.

Adopting a more permissive account of lineage-generating entities can be particularly useful at explaining different types of biological phenomena (Bapteste 2014; Bapteste et al. 2012; De Monte and Rainey 2014; Ereshefsky and Pedroso 2015; Corel et al. 2016; Dupré and O'Malley 2009). For example, De Monte and Rainey (2014) focus on the earlier stages of the evolution of multicellularity when parent-offspring relations are poorly defined. In order to represent these earlier stages, De Monte and Rainey allow two aggregates to be considered as genealogically related even when they only partly share their cell lineages. Their working hypothesis is that understanding the evolution of borderline cases of organisms is crucial for explaining how multicellular life evolved from single cells.

In conclusion, the case of microbial aggregates suggests that individual thinking might be especially useful for representing borderline cases of organisms. Microbial aggregates do not produce well-defined parent-offspring relations, but their component cell lineages are not randomly assembled either. In this way, microbial aggregates are lineage-generating entities in the sense that they facilitate the evolution of lineages within them by enabling some of their cell lineages to stick together. Multiple studies indicate that tracking cell lineages helps explain the dynamics of microbial aggregates and other biological phenomena, such as the evolution of multicellularity from unicellular ancestors. Therefore, representing microbial aggregates as biological individuals is not only feasible, but it also helps bridge the gap between the more theoretical literature on biological individuality and recent work on microbial communities.

\section{Acknowledgments}

I thank Matt Haber for multiple conversations on this topic, the audience in the workshop "Species in the Age of Discordance" at the 2017 Evolution Meeting (Portland, OR), and the constructive feedback received from the anonymous referees.

\section{Literature cited}

Abel, S., P. Zur Wiesch, B. Davis, and M. Waldor. 2015. "Analysis of Bottlenecks in Experimental Models of Infection.” PLoS Pathogens 11 (6): e1004823. doi:10.1371/journal.ppat.1004823.

Bapteste, E. 2014. “The Origins of Microbial Adaptations: How Introgressive Descent, Egalitarian Evolutionary Transitions and Expanded Kin Selection Shape the Network of Life." Frontiers in Microbiology 5. doi:10.3389/fmicb.2014.00083.

Bapteste, E., P. Lopez, F. Bouchard, F. Baquero, J. Mcinerney, and R. Burian. 2012. "Evolutionary Analyses of Non-Genealogical Bonds Produced by Introgressive Descent." Proceedings of the National Academy of Sciences 109 (45): 18266-18272. doi:10.1073/pnas.1206541109. 
Bonner, J. 1998. "The Origins of Multicellularity." Integrative Biology 1 (1): 27-36.

Boon, E., C. Meehan, C. Whidden, D. Wong, M. Langille, and R. Beiko. 2014. "Interactions in the Microbiome: Communities of Organisms and Communities of Genes." FEMS Microbiology Reviews 38 (1): 90-118. doi:10.1111/1574-6976.12035.

Booth, A. 2014. "Symbiosis, Selection, and Individuality." Biology and Philosophy 29:657-673. doi:10. 1007/s10539-014-9449-8.

Bouchard, F., and P. Huneman, eds. 2013. From Groups to Individuals: Evolution and Emerging Individuality. The MIT Press.

Bourke, A. 2011. Principles of Social Evolution. Oxford University Press.

Boyd, R. 1999. "Homeostasis, Species, and Higher Taxa." In Species: New Interdisciplinary Essays, edited by R. A. Wilson, 141-85. Cambridge: The MIT Press.

Burke, C., P. Steinberg, D. Rusch, S. Kjelleberg, and T. Thomas. 2011. "Bacterial Community Assembly Based on Functional Genes Rather Than Species." Proceedings of the National Academy of Sciences 108 (34): 14288-14293. doi:10.1073/pnas.1101591108.

Cahill, J., Z. Fan, I. Gronau, J. Robinson, J. Pollinger, B. Shapiro, J. Wall, et al. 2016. "WholeGenome Sequence Analysis Shows That Two Endemic Species of North American Wolf Are Admixtures of The Coyote and Gray Wolf." Science Advances 2 (7): e1501714. doi:10.1126/sciadv. 1501714.

Chiu, L., and G. Eberl. 2016. "Microorganisms as Scaffolds of Host Individuality: An Eco-Immunity Account of the Holobiont." Biology and Philosophy 31 (6): 819-837. doi:10.1007/s10539-0169552-0.

Claessen, D., D. Rozen, O. P. Kuipers, L. Søgaard-Andersen, and G. Van Wezel. 2014. "Bacterial Solutions to Multicellularity: A Tale of Biofilms, Filaments and Fruiting Bodies." Nature Revierws Microbiology 12:115-124. doi:10.1038/nrmicro3178.

Clarke, E. 2010. “The Problem of Biological Individuality.” Biological Theory 5:312-325. doi:10.1162/ biot_a_00068.

Clarke, E. 2013. “The Multiple Realizability of Biological Individuals.” The Journal of Philosophy CX:413-435. doi:10.5840/jphil2013110817.

Clarke, E. 2016. "Levels of Selection in Biofilms: Multispecies Biofilms Are Not Evolutionary Individuals." Biology and Philosophy 31:191-212. doi:10.1007/s10539-016-9517-3.

Clarke, E., and S. Okasha. 2013. "Species and Organisms: What Are the Problems?” In From Groups to Individuals: Evolution and Emerging Individuality, edited by F. Bouchard and P. Huneman, 5575. MIT Press.

Corel, E., P. Lopez, R. Méheust, and E. Bapteste. 2016. "Network-Thinking: Graphs to Analyze Microbial Complexity and Evolution." Trends in Microbiology 24:224-237. doi:10.1016/j.tim.2015. 12.003.

Coyne, J., and H. Orr. 2004. Speciation. Sunderland: Sinauer Associates, Inc.

De Monte, S., and P. Rainey. 2014. "Nascent Multicellular Life and the Emergence Of Individuality." Journal of Biosciences 39 (2): 237-248. doi:10.1007/s12038-014-9420-5.

De Queiroz, K. 1998. “The General Lineage Concept of Species, Species Criteria, and the Process of Speciation,” edited by D. Howard and S. Berlocher, 57-75. Oxford University Press. 
De Queiroz, K. 2007. “Species Concepts and Species Delimitation.” Systematic Biology 56:866-879. doi:10.1080/10635150701701083.

Devitt, M. 2008. “Resurrecting Biological Essentialism.” Philosophy of Science 75:344-382. doi:10.1086 1593566.

Díaz-Muñoz, S., A. Boddy, G. Dantas, C. Waters, and J. Bronstein. 2016. "Contextual Organismality: Beyond Pattern to Process in the Emergence of Organisms.” Evolution. doi:10.1111/evo.13078.

Doolittle, W. 2013. "Microbial Neopleomorphism.” Biology and Philosophy 28 (2): 351-378. doi:10. 1007/s10539-012-9358-7.

Doolittle, W., and A. Booth. 2017. "It's the Song, Not the Singer: An Exploration of Holobiosis and Evolutionary Theory." Biology and Philosophy 32 (1): 5-24. doi:10.1007/s10539-016-9542-2.

Dupré, J., John, and M. A. O’Malley. 2009. "Varieties of Living Things: Life at the Intersection of Lineage and Metabolism." Philosophy and Theory in Biology 1 (3). doi:10.3998/ptb.6959004.0001. 003.

Eldredge, N. 1985. Unfinished Synthesis: Biological Hierarchies and Modern Evolutionary Thought. Oxford University Press.

Elias, S., and E. Banin. 2012. "Multi-Species Biofilms: Living with Friendly Neighbors." FEMS Microbiology Reviews: 1-15. doi:10.1111/j.1574-6976.2012.00325.x.

Ereshefsky, M. 2001. The Poverty of the Linnaean Hierarchy: A Philosophical Study of Biological Taxonomy. Cambridge: Cambridge University Press.

Ereshefsky, M. 2010. "What's Wrong With the New Biological Essentialism." Philosophy of Science 77:674-685. doi:10.1086/656545.

Ereshefsky, M. 2014. “Species, Historicity, and Path Dependency.” Philosophy of Science 81 (5): 714726. doi:10.1086/677202.

Ereshefsky, M., and M. Pedroso. 2013. "Biological Individuality: The Case of Biofilms." Biology and Philosophy 28:331-349. doi:10.1007/s10539-012-9340-4.

Ereshefsky, M., and M. Pedroso. 2015. "Rethinking Evolutionary Individuality." Proceedings of the National Academy of Sciences 112:10126-10132. doi:10.1073/pnas.1421377112.

Flemming, H.-C., and J. Wingender. 2010. “The Biofilm Matrix.” Nature Reviews Microbiology 8:623633. doi:10.1038/nrmicro2415.

Fletcher, J., and M. Doebeli. 2009. "A Simple and General Explanation for the Evolution of Altruism." Proceedings of the Royal Society B: Biological Sciences 276 (1654): 13-19. doi:10.1098/rspb. 2008.0829.

Folse, H., III, and J. Roughgarden. 2010. "What Is an Individual Organism? A Multilevel Selection Perspective." The Quarterly Review of Biology 85:447-472. doi:10.1086/656905.

Gadagkar, R., and J. Bonner. 1994. "Social Insects and Social Amoebae." Journal of Biosciences 19 (2): 219-245. doi:10.1007/BF02703057.

Ghiselin, M. T. 1974. “A Radical Solution to the Species Problem.” Systematic Zoology 23:536-544. doi:10.1093/sysbio/23.4.536.

Gilbert, O., and K. et al. Foster. 2007. "High Relatedness Maintains Multicellular Cooperation in a Social Amoeba by Controlling Cheater Mutants." Proceedings of the National Academy of Sciences 104:8973-8917. doi:10.1073/pnas.0702723104. 
Godfrey-Smith, P. 2013. “Darwinian Individuals.” In From Groups to Individuals: Evolution and Emerging Individuality, edited by F. Bouchard and P. Huneman, 17-36. The MIT Press.

Godfrey-Smith, P. 2015. "Reproduction, Symbiosis, and the Eukaryotic Cell." Proceedings of the National Academy of Sciences 112 (33): 10120-10125. doi:10.1073/pnas.1421378112.

Griesemer, J. 2016. "Reproduction in Complex Life Cycles: Toward a Developmental Reaction Norms Perspective.” Philosophy of Science 83 (5): 803-815. doi:10.1086/687865.

Griffin, A., S. West, and A. Buckling. 2004. "Cooperation and Competition in Pathogenic Bacteria." Nature 430 (7003): 1024-1027. doi:10.1038/nature02744.

Grosberg, R. K., and R. R. Strathmann. 2007. "The Evolution of Multicellularity: A Minor Major Transition?" Annual Review of Ecology, Evolution, and Systematics: 621-654. doi:10.1146/annurev. ecolsys.36.102403.114735.

Haber, M. 2012. "Multilevel Lineages and Multidimensional Trees: The Levels of Lineage and Phylogeny Reconstruction." Philosophy of Science 79 (5): 609-623. doi:10.1086/667849.

Haber, M. 2013. “Colonies Are Individuals: Revisiting The Superorganism Revival.” In From Groups to Individuals: Evolution and Emerging Individuality, edited by F. Bouchard and P. Huneman, 17594. The MIT Press.

Haber, M. 2016. “The Individuality Thesis (3 Ways).” Biology and Philosophy 31 (6): 913-930. doi:10. 1007/s10539-016-9548-9.

Hall-Stoodley, L., J. Costerton, and P. Stoodley. 2004. "Bacterial Biofilms: From the Natural Environment To Infectious Diseases.” Nature Reviews Microbiology 2:95-108. doi:10.1038/nrmicro821.

Hall-Stoodley, L., and P. Stoodley. 2005. "Biofilm Formation and Dispersal and the Transmission of Human Pathogens.” Trends in Microbiology 13 (1): 7-10. doi:10.1016/j.tim.2004.11.004.

Hansen, S., P. Rainey, J. Haagensen, and S. Molin. 2007. "Evolution of Species Interactions in a Biofilm Community.” Nature 445 (7127): 533-536. doi:10.1038/nature05514.

Herron, M. D., A. Rashidi, D. Shelton, and W. Driscoll. 2013. "Cellular Differentiation and Individuality in The 'Minor' Multicellular Taxa." Biological Reviews 88 (4): 844-861. doi:10.1111/brv. 12031.

Hull, D. 1980. "Individuality and Selection." Annual Review of Ecology and Systematics 11:311-332. doi:10.1146/annurev.es.11.110180.001523.

Hull, D. L. 1978. “A Matter of Individuality.” Philosophy of Science 45:335-360. doi:10.1086/288811.

Huneman, P. 2013. "Adaptations in Transitions: How to Make Sense of Adaptation when Beneficiaries Emerge Simultaneously with Benefits?" In From Groups to Individuals: Evolution and Emerging Individuality, edited by F. Bouchard and P. Huneman, 141-72. The MIT Press.

Kobayashi, K. 2007. "Bacillus subtilis Pellicle Formation Proceeds through Genetically Defined Morphological Changes.” Journal of Bacteriology 189 (13): 4920-4931. doi:10.1128/jb.00157-07.

Kolenbrander, P., R. Palmer Jr., S. Periasamy, and N. Jakubovics. 2010. "Oral Multispecies Biofilm Development and the Key Role of Cell-Cell Distance." Nature Revierws Microbiology 8:471-480. doi:10.1038/nrmicro2381.

Kreft, J. 2004. “Biofilms Promote Altruism.” Microbiology 150 (8): 2751-2760. doi:10.1099/mic.0. 26829-0.

Laporte, J. 2004. Natural Kinds and Conceptual Change. Cambridge: Cambridge University Press. 
Leigh, E. 1995. “The Major Transitions of Evolution.” Evolution. doi:10.1111/j.1558-5646.1995. tb04464.x.

Lewontin, R. 1970. "The Units of Selection." Annual Review of Ecology and Systematics 1:1-18. doi:10. 1146/annurev.es.01.110170.000245.

Lloyd, E. 2012. "Units and Levels of Selection.” http://plato.stanford.edu/archives/spr2012/entries/ selection-units/.

McConwell, A. 2017. "Contingency and Individuality: A Plurality of Evolutionary Individuality Types.” Philosophy of Science. doi:10.1086/694010.

McDougald, D., S. A. Rice, N. Barraud, P. D. Steinberg, and S. Kjelleberg. 2011. "Should We Stay or Should We Go: Mechanisms and Ecological Consequences for Biofilm Dispersal.” Nature Reviews Microbiology 10 (November): 39-50. https://doi.org/10.1038/nrmicro2695.

Millet, Y., D. Alvarez, S. Ringgaard, U. von Andrian, B. Davis, and M. Waldor. 2014. "Insights into Vibrio Cholerae Intestinal Colonization from Monitoring Fluorescently Labeled Bacteria." PLoS Pathogens 10 (10): e1004405. doi:10.1371/journal.ppat.1004405.

Mishler, B. 1999. "Getting Rid of Species?” In Species: New Interdisciplinary Essays, edited by R. Wilson, 307-15. Cambridge: MIT Press.

Morris, J., R. Lenski, and E. Zinser. 2012. "The Black Queen Hypothesis: Evolution of Dependencies through Adaptive Gene Loss." MBio 3 (2): e00036-12. doi:10.1128/mbio.00036-12.

Nadell, C., K. Drescher, and K. Foster. 2016. "Spatial Structure, Cooperation and Competition on Biofilms.” Nature Reviews Microbiology: 589-600. doi:10.1038/nrmicro.2016.84.

Nadell, C., K. Foster, and J. Xavier. 2010. "Emergence of Spatial Structure in Cell Groups and the Evolution of Cooperation.” PLoS Computational Biology 6 (3): e1000716. doi:10.1371/journal. pcbi.1000716.

Nadell, C., J. Xavier, and K. Foster. 2009. "The Sociobiology of Biofilms.” FEMS Microbiology Reviews 33:206-224. doi:10.1111/j.1574-6976.2008.00150.x.

O’Malley, M., and J. Dupré John. 2007. “Size Doesn't Matter: Towards a More Inclusive Philosophy of Biology.” Biology and Philosophy 22:155-191. doi:10.1007/s10539-006-9031-0.

Okasha, S. 2002. "Darwinian Metaphysics: Species and the Question of Essentialism." Synthese 131:191-213. doi:10.1023/A:1015731831011.

Palmer, R., K. Kazmerzak, M. Hansen, and P. Kolenbrander. 2001. "Mutualism versus Independence: Strategies of Mixed-Species Oral Biofilms In Vitro Using Saliva as the Sole Nutrient Source.” Infection and Immunity 69:5794-5804. doi:10.1128/iai.69.9.5794-5804.2001.

Pedroso, M. 2017. "Inheritance by Recruitment: A Reply to Clarke's 'Levels of Selection in Biofilms'." Biology and Philosophy 32:127-131. doi:10.1007/s10539-016-9536-0.

Pedroso, M. 2018. “The Impact of Population Bottlenecks on the Social Lives of Microbes." Biological Theory 13:190-198. doi:10.1007/s13752-018-0298-6.

Pepper, J., and M. Herron. 2008. “Does Biology Need an Organism Concept?” Biological Reviews 83 (4): 621-627. doi:10.1111/j.1469-185x.2008.00057.x.

Pradeu, T. 2012. The Limits of the Self: Immunology and Biological Identity. Oxford University Press.

Queller, D. 1997. “Cooperators Since Life Began.” Quarterly Review of Biology. doi:10.1086/419766. 
Queller, D., and J. Strassmann. 2009. "Beyond Society: The Evolution of Organismality." Philosophical Transactions of the Royal Society B. 364:3143-3155. doi:10.1098/rstb.2009.0095.

Queller, D., and J. Strassmann. 2016. "Problems of Multi-Species Organisms: Endosymbionts to Holobionts." Biology and Philosophy. doi:10.1007/s10539-016-9547-x.

Rainey, P., and S. De Monte. 2014. "Resolving Conflicts During the Evolutionary Transition to Multicellular Life." Annual Review of Ecology, Evolution, and Systematics 45:599-620. doi:10.1146/ annurev-ecolsys-120213-091740.

Ratcliff, W., R. Denison, M. Borrello, and M. Travisano. 2012. "Experimental Evolution of Multicellularity." Proceedings of the National Academy of Sciences 109 (5): 1595-1600. doi:10.1073/pnas. 1115323109.

Ratcliff, W., J. Fankhauser, D. Rogers, D. Greig, and M. Travisano. 2015. "Origins of Multicellular Evolvability in Snowflake Yeast.” Nature Communications 6. doi:10.1038/ncomms7102.

Richards, R. 2010. The Species Problem: A Philosophical Analysis. Cambridge: Cambridge University Press.

Rickard, A., P. Gilbert, N. High, P. Kolenbrander, and P. Handley. 2003. "Bacterial Coaggregation: An Integral Process in The Development of Multi-Species Biofilms.” Trends in Microbiology 11:94-100. doi:10.1016/s0966-842x(02)00034-3.

Santelices, B. 1999. "How Many Kinds of Individuals Are There?" Trends in Ecology and Evolution 14:152-155. doi:10.1016/s0169-5347(98)01519-5.

Schirrmeister, B., A. Antonelli, and H. Bagheri. 2011. "The Origin of Multicellularity in Cyanobacteria." BMC Evolutionary Biology 11 (1): 45. doi:10.1186/1471-2148-11-45.

Skillings, D. 2016. "Holobionts and the Ecology of Organisms: Multi-Species Communities or Integrated Individuals?” Biology and Philosophy 31 (6): 875-892. doi:10.1007/s10539-016-9544-0.

Sober, E. 1980. "Evolution, Population Thinking, and Essentialism.” Philosophy of Science 47:350-383. doi:10.1086/288942.

Sterner, B. 2017. “Individuating Population Lineages: A New Genealogical Criterion.” Biology and Philosophy 32 (5): 683-703. doi:10.1007/s10539-017-9580-4.

Stewart, P., and M. Franklin. 2008. "Physiological Heterogeneity in Biofilms." Nature Revierws Microbiology 6:199-210. doi:10.1038/nrmicro1838.

Strassmann, J., O. Gilbert, and D. Queller. 2011. "Kin Discrimination and Cooperation in Microbes." Annual Review of Microbiology 65:349-367. doi:10.1146/annurev.micro.112408.134109.

Tarnita, C., C. Taubes, and M. Nowak. 2013. "Evolutionary Construction by Staying Together and Coming Together.” Journal of Theoretical Biology 320:10-22. doi:10.1016/j.jtbi.2012.11.022.

Van Gestel, J., F. Weissing, O. Kuipers, and A. Kovács. 2014. "Density of Founder Cells Affects Spatial Pattern Formation and Cooperation in Bacillus subtilis Biofilms." The ISME Journal 8:20692079. doi:10.1038/ismej.2014.52.

Vlamakis, H., Y. Chai, P. Beauregard, R. Losick, and R. Kolter. 2013. "Sticking Together: Building a Biofilm the Bacillus Subtilis Way.” Nature Reviews Microbiology 11 (3): 157-168. doi:10.1038/ nrmicro2960.

Vrba, E., and N. Eldredge. 1984. "Individuals, Hierarchies and Processes: Towards A More Complete Evolutionary Theory.” Paleobiology 10 (2): 146-171. doi:10.1017/s0094837300008149. 
Wilson, D., and E. Sober. 1989. "Reviving the Superorganism." Journal of Theoretical Biology 136:337356. doi:10.1016/s0022-5193(89)80169-9.

(C) 2019 Author(s)

This is an open-access article distributed under the terms of the Creative Commons Attribution 4.0 International license, which permits anyone to download, copy, distribute, display, or adapt the text without asking for permission, provided that the creator(s) are given full credit.

ISSN 2475-3025 